\title{
Exploiting air cushion effects to optimise a superhydrophobic/hydrophilic patterned liquid ring sealed air bearing
}

\author{
Jun Wen ${ }^{1}$, Tom Reddyhoff, Songtao Hu, Debashis Puhan, Daniele Dini \\ Tribology Group, Department of Mechanical Engineering, South Kensington Campus, Exhibition \\ Road, London SW7 2AZ, UK
}

\begin{abstract}
A thrust bearing consisting of an air cushion formed within a liquid ring has been developed, which takes advantage of the Laplace pressure induced by the liquid/air surface tension. As forces induced by Laplace pressure and surface tension scales down much more slowly than gravity and inertial forces, such a bearing has great potential when scaled down to the micro-scale. The liquid ring between the rotor and the stator of the bearing is anchored there by alternating hydrophilic and superhydrophobic patterns. An important discovery is that the performance of this bearing is greatly enhanced by the sealed cushion of air within the ring. This air cushion and thin liquid ring arrangement mean that the solid/solid contact of the bearing is replaced by solid/air and solid/liquid contact which significantly reduces the friction and wear. The factors which affects the performance of the bearing have been studied both experimentally and numerically providing results that can be used to optimise the design of this new type of bearing.
\end{abstract}

${ }^{1}$ Corresponding author: j.wen17@imperial.ac.uk 


\begin{tabular}{|c|c|c|c|}
\hline \multicolumn{4}{|c|}{ Nomenclature } \\
\hline$R$ & radius of the bearing & $R_{\text {in }}$ & inner radius of the hydrophilic strip \\
\hline$R_{\text {out }}$ & outer radius of the hydrophilic strip & $h$ & gap height of the bearing \\
\hline$F_{\text {Supporting }}$ & supporting force of the bearing & $F_{\text {Laplace }}$ & $\begin{array}{l}\text { vertical force induced by the Laplace } \\
\text { pressure }\end{array}$ \\
\hline$F_{\text {Capillary }}$ & $\begin{array}{l}\text { vertical component of the capillary } \\
\text { force }\end{array}$ & $\gamma_{\mathrm{LA}}$ & liquid/air surface tension \\
\hline$\theta_{\text {in }}$ & $\begin{array}{l}\text { inner local contact angle of the } \\
\text { liquid ring }\end{array}$ & $\theta_{\text {out }}$ & $\begin{array}{l}\text { outer local contact angle of the liquid } \\
\text { ring }\end{array}$ \\
\hline$\varphi$ & $\begin{array}{l}\text { circumferential angle in the } \\
\text { coordinate system }\end{array}$ & $O_{\mathrm{U}}$ & center point of the upper patterns \\
\hline$O_{\mathrm{L}}$ & center point of the lower patterns & $O_{\mathrm{s}}$ & origin of the coordinate system \\
\hline$\Delta P_{\text {in }}$ & $\begin{array}{l}\text { Laplace pressure crossing the inner } \\
\text { meniscus of the liquid ring }\end{array}$ & $\Delta P_{\text {out }}$ & $\begin{array}{l}\text { Laplace pressure crossing the outer } \\
\text { meniscus of the liquid ring }\end{array}$ \\
\hline$r_{\text {in }}$ & $\begin{array}{l}\text { mean curvature radius of the inner } \\
\text { meniscus }\end{array}$ & $r_{\text {out }}$ & $\begin{array}{l}\text { mean curvature radius of the outer } \\
\text { meniscus }\end{array}$ \\
\hline$r_{1 \text { in }}$ & $\begin{array}{l}\text { curvature radius of the inner } \\
\text { meniscus on the cross-sectional } \\
\text { plane }\end{array}$ & $r_{1 \text { out }}$ & $\begin{array}{l}\text { curvature radius of the outer } \\
\text { meniscus on the cross-sectional plane }\end{array}$ \\
\hline$r_{\text {2in }}$ & $\begin{array}{l}\text { curvature radius of the inner } \\
\text { meniscus on the horizontal plane }\end{array}$ & $r_{\text {2out }}$ & $\begin{array}{l}\text { curvature radius of the outer } \\
\text { meniscus on the horizontal plane }\end{array}$ \\
\hline$\theta_{\text {inmin }}$ & $\begin{array}{l}\text { minimum inner local contact angle } \\
\text { of the liquid ring }\end{array}$ & $\theta_{\text {outmax }}$ & $\begin{array}{l}\text { maximum outer local contact angle } \\
\text { of the liquid ring }\end{array}$ \\
\hline$\eta$ & kinematic viscosity of water & $\Delta R_{\mathrm{in}}{ }^{\prime}$ & $\begin{array}{l}\text { local misalignment of the inner } \\
\text { contact line }\end{array}$ \\
\hline$\Delta R$ & $\begin{array}{l}\text { misalignment of the patterns on the } \\
\text { rotor and stator }\end{array}$ & $W_{\text {ring }}$ & width of the liquid ring \\
\hline$\Delta R_{\text {out }}{ }^{\prime}$ & $\begin{array}{l}\text { local misalignment of the outer } \\
\text { contact line }\end{array}$ & $\theta_{\text {phiR }}$ & $\begin{array}{l}\text { receding contact angle on the } \\
\text { hydrophilic surface }\end{array}$ \\
\hline$\theta_{\text {phoA }}$ & $\begin{array}{l}\text { advancing contact angle on the } \\
\text { superhydrophilic surface }\end{array}$ & $n$ & $\begin{array}{l}\text { molar mass of the air inside the air } \\
\text { cushion }\end{array}$ \\
\hline $\mathrm{R}_{\text {gas }}$ & ideal gas constant & $\mathrm{T}$ & temperature \\
\hline$P_{\text {air }}$ & pressure inside the air cushion & $V_{\text {air }}$ & volume of the air cushion \\
\hline$V_{\text {ring }}$ & volume of the liquid ring & $\alpha$ & liquid evaporation coefficient \\
\hline $\mathrm{v}$ & air flow velocity around the bearing & $\mathrm{A}$ & area of the outer liquid/air interface \\
\hline$L_{e}$ & $\begin{array}{l}\text { amount of liquid evaporated per } \\
\text { second }\end{array}$ & $X$ & $\begin{array}{l}\text { Actual humidity ratio of the } \\
\text { environmental air }\end{array}$ \\
\hline$X_{s}$ & $\begin{array}{l}\text { maximum humidity ratio of the } \\
\text { environmental air }\end{array}$ & $C_{j}$ & $\begin{array}{l}\text { concentration of gas } j \text { in the liquid } \\
\text { ring }\end{array}$ \\
\hline$K_{H j}$ & Henrry's constant of gas $j$ & $t$ & time \\
\hline$P_{j}$ & partial pressure of gas $j$ & $\Delta n_{j}$ & $\begin{array}{l}\text { molar mass of gas } j \text { diffused through } \\
\text { the liquid ring }\end{array}$ \\
\hline$D_{j}$ & $\begin{array}{l}\text { diffusion coefficient of gas } j \text { in the } \\
\text { liquid }\end{array}$ & $\rho$ & density of water \\
\hline$T$ & frictional torque exerted on the rotor & $\Omega$ & rotational speed of the rotor \\
\hline K & stiffness coefficient of the bearing & & \\
\hline
\end{tabular}




\section{Introduction}

Governed by the scaling laws, the magnitudes of different types of forces vary differently with length scale $[1,2]$. As a result, forces induced by surface tension which, under most circumstances are negligible compared to gravity and inertial forces at the macroscale, dominate at the micrometer and lower scales [3, 4]. Two typical forces which behave in this way are the force induced by surface tension acting on the contact line of a liquid/gas interface and the force due to Laplace pressure acting on the surface enclosed in a liquid/air interface [5]. As length decreases, these scale linearly [3] and hence decrease more slowly than body force and weight. Because of this, these two forces have been utilized in many small scale mechanical manipulators, such as self-assembly [6, 7], actuation [8, 9], lubrication [10-13], grasp and release [14, 15]. A practical example is the liquid bridge [5, 16, 17] spanning the gap between two solid surfaces. This shows either an attractive or a repulsive axial force depending on its volume, the gap height, and the contact angles on the solid surfaces [18, 19]. To take advantage of the repulsive case, liquid bridge thrust bearings have been developed [10-13]. Such bearings contain two plates which serve as a rotor and a stator. The confronting faces of the two plates were coated with alternating hydrophobic and hydrophilic patterns which anchor liquid bridges on the hydrophilic area. Thrust bearings with different shapes and distributions of liquid bridges have been studied, including a single liquid column [10, 13], a liquid column with surrounding droplets [12], and concentric liquid rings $[11,20]$. Liquid bridges located at different positions provide different functions such as load support, lateral force resistance and tilting resistance, however, they all operate under the same fundamental mechanisms. When compressed, Laplace pressure builds up inside those liquid bridges which provide a repulsive force to support the load on the rotor. Thus, the solid/solid contact between the rotor and stator is replaced by liquid/solid contact which reduces frictional torque and wear. The annularly scattered satellite droplets provide a resisting moment when the rotor tilts. The capillary force which acts on the contact line has a resultant horizontal component when there is a misalignment between the upper and lower patterns which balances the lateral force applied to the rotor. For these bearings, the supporting force originates from the Laplace pressure inside water droplet/ring. Thus for a given gap height, the maximum supporting force increases linearly with the wetted area inside the liquid bridges. However the frictional torque exerted on the rotor also increases with the wetted area [20].

Another effective technique of lubrication at the millimeter and micrometer scales is the air levitated bearing [21-23]. The rotor of this bearing is levitated by pressurised air flow and thus the solid/solid contact is replaced by air/solid contact which dramatically reduces the friction and wear. However, these bearings need a continuous air supply and a complex control system.

In this study, an air levitated thrust bearing has been designed without need for a continuous supply of air. It is shown for the first time that an air cushion between rotor and stator can be maintained by a liquid ring, in this case water. In contrast to liquid bridge lubricated bearings in which the supporting force results from the wetted area, the supporting force of the liquid ring sealed air bearing results mainly from the sealed air cushion. Consequently, the latter has much higher supporting force and smaller frictional torque for the same rotor diameter. The variation of the supporting force, the stiffness and the frictional torque of the bearing as a function of the gap height and the rotational speed were investigated both experimentally and numerically. Effects of misalignment, air diffusion and liquid evaporation on the performance of the bearing were also assessed and discussed. The validated results can be used to design such bearings at smaller scales. 


\section{Methods}

\subsection{Bearing design and experimental method}

Taking advantage of the Laplace pressure at millimeter and micrometer scales, thrust bearings lubricated by liquid droplets, bridges and rings have been invented and investigated. Inspired by these, we report on a new design of air bearing, sealed by a liquid ring, which provides increased load capacity and decreased frictional torque. The liquid ring sealed air bearing developed here consists of a rotor, a stator, an air cushion and a liquid ring (shown in Fig. 1). The rotor and stator of the bearing are two aluminium parallel plates with a radius of $R=20 \mathrm{~mm}$. The inward facing surfaces of the plates were coated with Ultra-Ever Dry top coat (Ultra Tech International) with annular shaped tapes (characterised by a width of $2 \mathrm{~mm}$ and an inner diameter of $16 \mathrm{~mm}$ ) pasted concentrically on the plates. Tapes were removed later when the coating was dry thus leaving annular hydrophilic patterns (the hydrophilic plate surface protected by the tapes from superhydrophobic coating) alternating with coated superhydrophobic patterns. The inner and outer radii of the hydrophilic strip are $R_{\text {in }}=16 \mathrm{~mm}$ and $R_{\text {out }}=18 \mathrm{~mm}$ giving a strip width of $2 \mathrm{~mm}$. A rheometer (DHR-1, TA Instrument, USA) was used to measure the supporting force and the frictional torque of the bearing. The rotor and the stator were attached to the main axle and the base of the rheometer respectively. In the experiments, the temperature (T) was set to $25^{\circ} \mathrm{C}$. The static supporting force was defined as the supporting force measured when the bearing was being compressed without rotating. To measure this, a known volume of liquid was first injected onto the hydrophilic strip of the stator. The liquid was trapped there by the surface free energy barrier at the boundary of the alternating hydrophilic and superhydrophobic patterns. Then, the rotor moved down gradually with the main axle of the rheometer to compress the liquid. During this movement, the force exerted on the axle (i.e. the supporting force of the bearing) was recorded at 0.2micron intervals. When the liquid ring and the air cushion were compressed, the Laplace pressure, (i.e. the pressure difference across a curved liquid/air interface), started to build up inside the liquid ring and the air cushion. The Laplace pressure is directly proportional to the surface tension and the average curvature of the liquid/air interface and provides a force which supports the load on the rotor. The frictional torque and the dynamic supporting force of the bearing were measured simultaneously. The rotor was moved down and stopped at certain gap heights where the air cushion was compressed to give different supporting forces. Then, the rotational speed of the rotor was increased and measurements were taken at different speeds. Allowing $10 \mathrm{~s}$ for the rotor to stabilize, the frictional torque of the bearing was measured for $5 \mathrm{~s}$ at a rate of $2 \mathrm{~Hz}$.

There are many factors that influence the performance of the bearing. In this study, effects of misalignment between the patterns on the rotor and the stator, the liquid evaporation from the liquid ring and the air diffusion through the liquid ring have all been investigated.

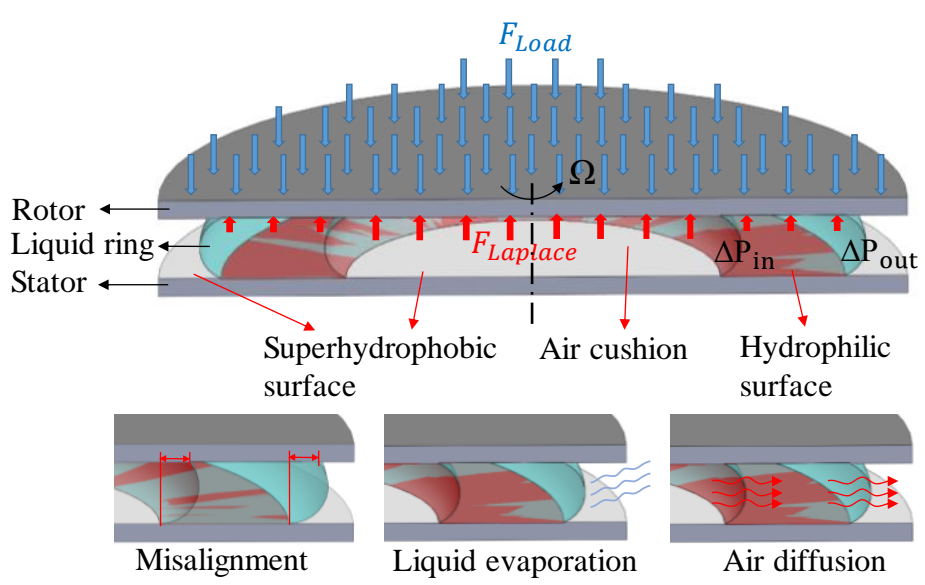

Fig. 1. Schematic diagram of the liquid ring sealed air bearing. 


\subsection{Theoretical model for the maximum static supporting force}

In this study, the gap height of the bearing ranged from 100 to $500 \mu \mathrm{m}$. At such small range of gap heights, the effect of gravitational acceleration could be neglected. Thus, the cross section of the liquid/air interface can be well approximated by an arc of constant radius. It should be noted here that there is a potential misalignment between the patterns on rotor and the stator (shown in Fig. 2(b) as $\Delta R$ ) and this turns out to be an important factor affecting the supporting force of the bearing. Thus, it is taken into account in the numerical model derived below. The supporting force of the bearing ( $F_{\text {Supporting }}$ ) results from the vertical component of the capillary force $\left(F_{\text {Capillary }}\right)$ acting on the contact line of the liquid ring and the vertical force induced by the Laplace pressure inside the liquid ring and the air cushion $\left(F_{\text {Laplace }}\right)$. The former is attractive and the latter is repulsive. Thus the supporting force is

$$
F_{\text {Supporting }}=F_{\text {Laplace }}-F_{\text {Capillary }}
$$

$F_{\text {Capillary }}$ is calculated using the following equation:

$$
F_{\text {Capillary }}=\int_{0}^{2 \pi} \gamma_{\mathrm{LA}} \cdot \cos \left(\theta_{\mathrm{in}}\right) \cdot R_{\mathrm{in}} \cdot d \varphi+\int_{0}^{2 \pi} \gamma_{\mathrm{LA}} \cdot \cos \left(\theta_{\mathrm{out}}-\pi / 2\right) \cdot R_{\text {out }} \cdot d \varphi
$$

where $\gamma_{\mathrm{LA}}$ is the surface tension of the liquid/air interface, $\theta_{\text {in }}$ and $\theta_{\text {out }}$ are the inner and outer local contact angles of the liquid ring (shown in Fig. 2 (b)) which vary with $\varphi$ (i.e. the circumferential angle in the coordinate system in Fig. $2(\mathrm{a})) . O_{\mathrm{U}}$ and $O_{\mathrm{L}}$ are the center points of the upper and lower coating patterns respectively. The origin of the coordinate system is $O_{\mathrm{s}}$ which is the midpoint between $O_{\mathrm{U}}$ and $O_{\mathrm{L}}$.

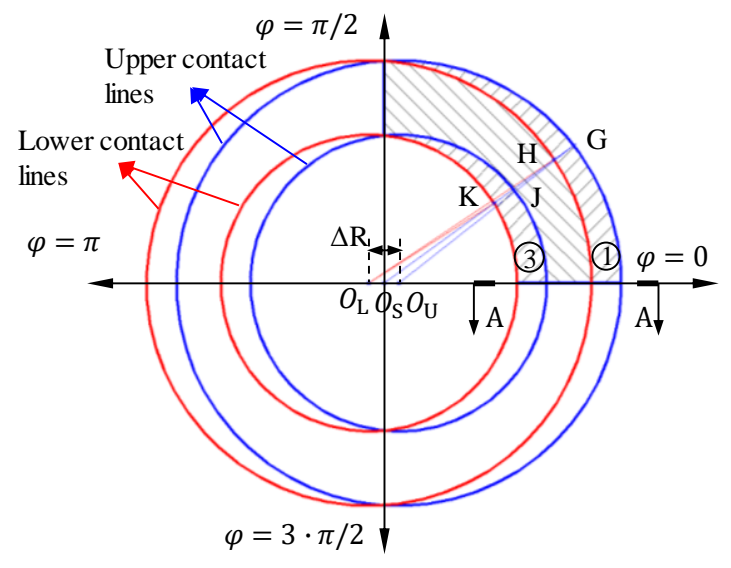

(a)

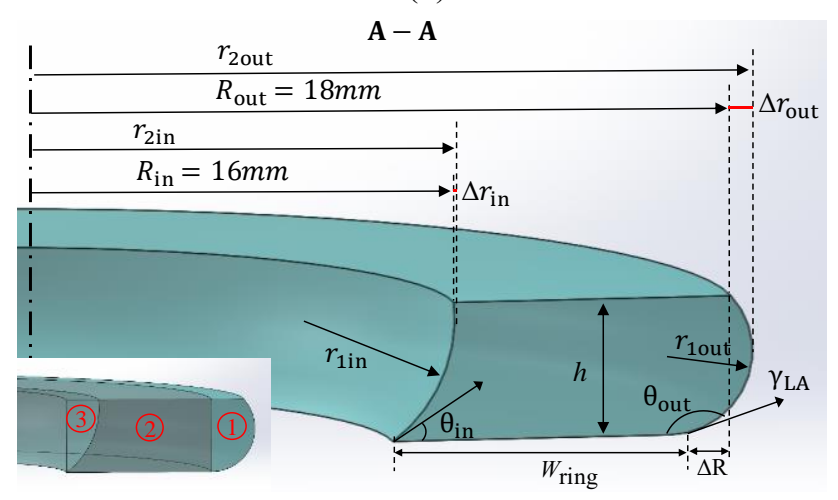

(b)

Fig. 2. Sketch of the bearing showing geometrical features in their most general configuration. (a) Sketch of the upper and lower contact lines of the liquid ring. (b) Cross-sectional view of the liquid ring at $\varphi=0$. 
$F_{\text {Laplace }}$ is calculated using the following equation:

$$
F_{\text {Laplace }}=\pi \cdot R_{\text {in }}^{2} \cdot \Delta P_{\text {in }}+\pi \cdot R_{\text {out }}^{2} \cdot \Delta P_{\text {out }}
$$

where $\Delta P_{\text {in }}$ and $\Delta P_{\text {out }}$ are the Laplace pressures crossing the inner and outer menisci of the liquid ring. These are calculated using the following equations [24]:

$$
\begin{gathered}
\Delta P_{\text {in }}=\gamma / r_{\text {in }}=\gamma \cdot\left(1 / r_{1 \text { in }}+1 / r_{\text {2in }}\right) \\
\Delta P_{\text {out }}=\gamma / r_{\text {out }}=\gamma \cdot\left(1 / r_{1 \text { out }}+1 / r_{\text {zout }}\right)
\end{gathered}
$$

where $r_{\text {in }}$ and $r_{\text {out }}$ are the mean curvature radii of the inner and outer menisci. $r_{1 \text { in }}\left(r_{2 \text { in }}\right)$ and $r_{1 \text { out }}$ $\left(r_{\text {zout }}\right)$ are the curvature radii of the inner and outer menisci of the liquid ring on the cross-sectional (horizontal) plane. When the bearing is being compressed, the critical local contact angle of the liquid ring $\left(\theta_{\text {inmin }}\right.$ and $\left.\theta_{\text {outmax }}\right)$ appears at $\varphi=0$ and $\pi$ as this corresponds to the first occurrence of liquid ring collapse (due to maximum local misalignment). Thus, in the following analysis we only consider the stress state at the location $\varphi=0$ which is shown in Fig. 2 (b). The curvature radii on the crosssectional plane of the inner and outer menisci are calculated using the following equations:

$$
\begin{aligned}
& r_{\text {1in }}=\frac{\sqrt{(\Delta R)^{2}+h^{2}}}{2 \cdot \sin \left(\arctan \left(\frac{h}{\Delta R}\right)-\theta_{\text {inmin }}\right)} \\
& r_{\text {1out }}=\frac{-\sqrt{(\Delta R)^{2}+h^{2}}}{2 \sin \left(\theta_{\text {outmax }}+\arctan \left(\frac{h}{\Delta R}\right)\right)}
\end{aligned}
$$

where $\Delta R$ is the misalignment of the patterns on the rotor and stator, $h$ is the gap height. As $h$ is smaller than $500 \mu \mathrm{m}$, the effect of gravity can be neglected.

The inner and outer curvature radii of the liquid ring on the horizontal plane are $r_{2 \text { in }}=R_{\text {in }}+\Delta r_{2 \text { in }}$ and $r_{\text {2out }}=R_{\text {out }}+\Delta r_{\text {2out }}$, where $\Delta r_{\text {2in }}$ and $\Delta r_{\text {2out }}$ are represented with two red solid lines in Fig. 2 (b). Because $h$ is much smaller than the radius of the liquid ring, $\Delta r_{2 \text { in }}$ and $\Delta r_{2 o u t}$ are small enough to be neglected. Therefore, $r_{2 \text { in }}$ and $r_{\text {2out }}$ are approximated to be $R_{\text {in }}$ and $R_{\text {out }}$. Substituting equations (2) to (7) into (1), the static supporting force of the bearing is obtained as:

$$
\begin{aligned}
F_{\text {Supporting }}=\{ & \pi \cdot R_{\text {in }}{ }^{2} \cdot \gamma \cdot\left[\frac{2 \cdot \sin \left(\arctan \left(\frac{h}{\Delta R}\right)-\theta_{\text {inmin }}\right)}{\sqrt{(\Delta R)^{2}+h^{2}}}+1 / R_{\text {in }}\right]+\pi \cdot R_{\text {out }}{ }^{2} \cdot \gamma \\
& \left.\cdot\left[\frac{2 \sin \left(\theta_{\text {outmax }}+\arctan \left(\frac{h}{\Delta R}\right)\right)}{-\sqrt{(\Delta R)^{2}+h^{2}}}+1 / R_{\text {out }}\right]\right\} \\
& -\int_{0}^{2 \pi} \gamma_{\mathrm{LA}} \cdot \cos \left(\theta_{\text {in }}\right) \cdot R_{\text {in }} \cdot d \varphi \\
& -\int_{0}^{2 \pi} \gamma_{\mathrm{LA}} \cdot \cos \left(\theta_{\text {out }}-\pi / 2\right) \cdot R_{\text {out }} \cdot d \varphi
\end{aligned}
$$

It should be noted here that the pressure inside the air cushion and the liquid ring is constant. Thus, although $\theta_{\text {in }}$ and $\theta_{\text {out }}$ vary with $\varphi, r_{\text {in }}$ and $r_{\text {out }}$ must be constant in the circumferential direction (i.e. for different $\varphi$ ). Hence, because $r_{2 \text { in }}$ and $r_{\text {zout }}$ are approximated to be $R_{\text {in }}$ and $R_{\text {out }}$, which are constant, $r_{1 \text { in }}$ and $r_{1 \text { out }}$ should also be constant at different $\varphi$.

To calculate the supporting force of the bearing, $\theta_{\text {in }}$ and $\theta_{\text {out }}$ were determined as functions of $\varphi$. Before this, the local misalignment of the inner $\left(\Delta R_{\mathrm{in}}{ }^{\prime}\right)$ and outer $\left(\Delta R_{\text {out }}{ }^{\prime}\right)$ contact lines in the $O_{\mathrm{S}}$ coordinate system (shown in Fig. 2 (a)) are calculated: 
where

$$
\begin{aligned}
\Delta R_{\text {in }}{ }^{\prime} & =\mathrm{J} O_{\mathrm{S}}-\mathrm{KO}_{\mathrm{S}} \\
\Delta R_{\text {out }}{ }^{\prime} & =\mathrm{G} O_{\mathrm{S}}-\mathrm{H} O_{\mathrm{S}}
\end{aligned}
$$

$$
\begin{gathered}
\mathrm{J} O_{\mathrm{S}}=\cos (\varphi) \cdot \Delta R / 2+\sqrt{[\cos (\varphi)]^{2} \cdot \frac{\Delta R^{2}}{4}+R_{\mathrm{in}}^{2}-\frac{\Delta R^{2}}{4}} \\
\mathrm{~K} O_{\mathrm{S}}=\cos (\pi-\varphi) \cdot \Delta R / 2+\sqrt{[\cos (\pi-\varphi)]^{2} \cdot \frac{\Delta R^{2}}{4}+R_{\mathrm{in}}^{2}-\frac{\Delta R^{2}}{4}} \\
\mathrm{G} O_{\mathrm{S}}=\cos (\varphi) \cdot \Delta R / 2+\sqrt{[\cos (\varphi)]^{2} \cdot \frac{\Delta R^{2}}{4}+R_{\text {out }}^{2}-\frac{\Delta R^{2}}{4}} \\
\mathrm{H} O_{\mathrm{S}}=\cos (\pi-\varphi) \cdot \Delta R / 2+\sqrt{[\cos (\pi-\varphi)]^{2} \cdot \frac{\Delta R^{2}}{4}+R_{\text {out }}^{2}-\frac{\Delta R^{2}}{4}}
\end{gathered}
$$

As expected, $\Delta R_{\text {in }}{ }^{\prime}$ and $\Delta R_{\text {out }}{ }^{\prime}$ decrease from $\Delta R$ at $\varphi=0^{\circ}$ to 0 at $\varphi=90^{\circ}$. Next, through geometric reasoning, the equations for $\theta_{\text {in }}$ and $\theta_{\text {out }}$ are obtained as:

$$
\begin{gathered}
\theta_{\text {in }}=\tan ^{-1}\left(\frac{h}{\Delta R_{\text {in }}{ }^{\prime}}\right)+\cos ^{-1}\left(\frac{\sqrt{\Delta R_{\text {in }}{ }^{2}+h^{2}}}{2 \cdot r_{1 \text { in }}}\right)-\frac{\pi}{2} \\
\theta_{\text {out }}=\frac{3 \cdot \pi}{2}-\tan ^{-1}\left(\frac{h}{\Delta R_{\text {out }}{ }^{\prime}}\right)-\cos ^{-1}\left(\frac{\sqrt{\Delta R_{\text {out }}{ }^{\prime 2}+h^{2}}}{2 \cdot r_{1 \text { out }}}\right)
\end{gathered}
$$

When considering the maximum supporting force of the bearing, the critical values of the inner and outer contact angles, which are the receding contact angle on the hydrophilic surface $\left(\theta_{\text {phiR }}\right)$ and the advancing contact angle on the superhydrophilic surface $\left(\theta_{\text {phoA }}\right)$, are applied to $\theta_{\text {inmin }}$ and $\theta_{\text {outmax }}$ respectively. Using the equations above, the maximum supporting force of the bearing at a certain gap height can be obtained.

\subsection{Theoretical model for the stiffness of the bearing}

The model for the stiffness of the bearing simulates the supporting force, $F_{\text {Supporting, }}$, as a function of gap height, $h$, when the bearing is being compressed. Initially, the air cushion between rotor and stator is sealed but not compressed and the supporting force of the bearing was very small. It is assumed that the inner liquid/air interface is not curved and the initial value of $\theta_{\text {inmin }}$ was $\theta_{\text {inmin_init }}=\frac{\pi}{2}+$ $\arctan (\Delta R / h)$. As the initial supporting force of the bearing is known, the outer contact angle of the liquid ring is calculated. Through integration, the initial volume of the air cushion $\left(V_{\text {air_init }}\right)$ and the liquid ring ( $V_{\text {ring_init }}$ ) are obtained (see the method reported in the Appendix). Using the ideal gas state equation the initial molar mass of air $\left(n_{\text {init }}\right)$ inside the air cushion can be also obtained as:

$$
P_{\text {air_init }} \cdot V_{\text {air_init }}=n_{\text {init }} \cdot \mathrm{R}_{\text {gas }} \cdot \mathrm{T}
$$

where $n_{\text {init }}$ is the initial molar mass of the air inside the air cushion, and $\mathrm{R}_{\text {gas }}$ is the ideal gas constant.

Next, the gap height decreased by a small value and the equilibrium state at the new gap height was calculated. An iterative loop is used to calculate the new equilibrium state. In this loop, first $\theta_{\text {inmin }}$ is assigned a value. Then according to the volume conservation of the liquid ring, $\theta_{\text {outmax }}$ is obtained. A liquid evaporation model (discussed later in this section) which excludes the liquid evaporated during the compressing process is included here. With $\theta_{\text {inmin }}$ and $\theta_{\text {outmax }}$, the Laplace pressure and the 
volume of the air cushion after compression are obtained. Then, using Eq. (4) and (5), the pressure inside the air cushion $\left(P_{\text {air }}\right)$ is obtained. Moreover, $P_{\text {air }}$ is also calculated using the ideal gas state equation. An air diffusion model (discussed later in this section) is used here to exclude the diffusion of air through the liquid ring into the environment. When the two values of $P_{\mathrm{air}}$, calculated using the above two methods, become equal, the loop ends and the equilibrium state is obtained. After this, the supporting force of the bearing at the new gap height is obtained. It should be noted that as the contact angle varies, the contact line moves slightly. This effect is taken into account by the wettability transition model which will be discussed later. When $\theta_{\text {inmin }}$ reaches $\theta_{\text {phiR }}$, it stops decreasing and the inner contact line starts to slip which results in a larger $R_{\mathrm{in}}$. When $\theta_{\text {outmax }}$ reaches $\theta_{\mathrm{phoA}}$, the liquid ring collapses.

A flowchart showing the workflow and the pseudo-code used to determine the stiffness of the bearing is shown in Fig. 3. In the following sub-sections the details of the water evaporation, air diffusion and slip models, specifically identified as main items contributing to in the flow chart, will be discussed in more detail.

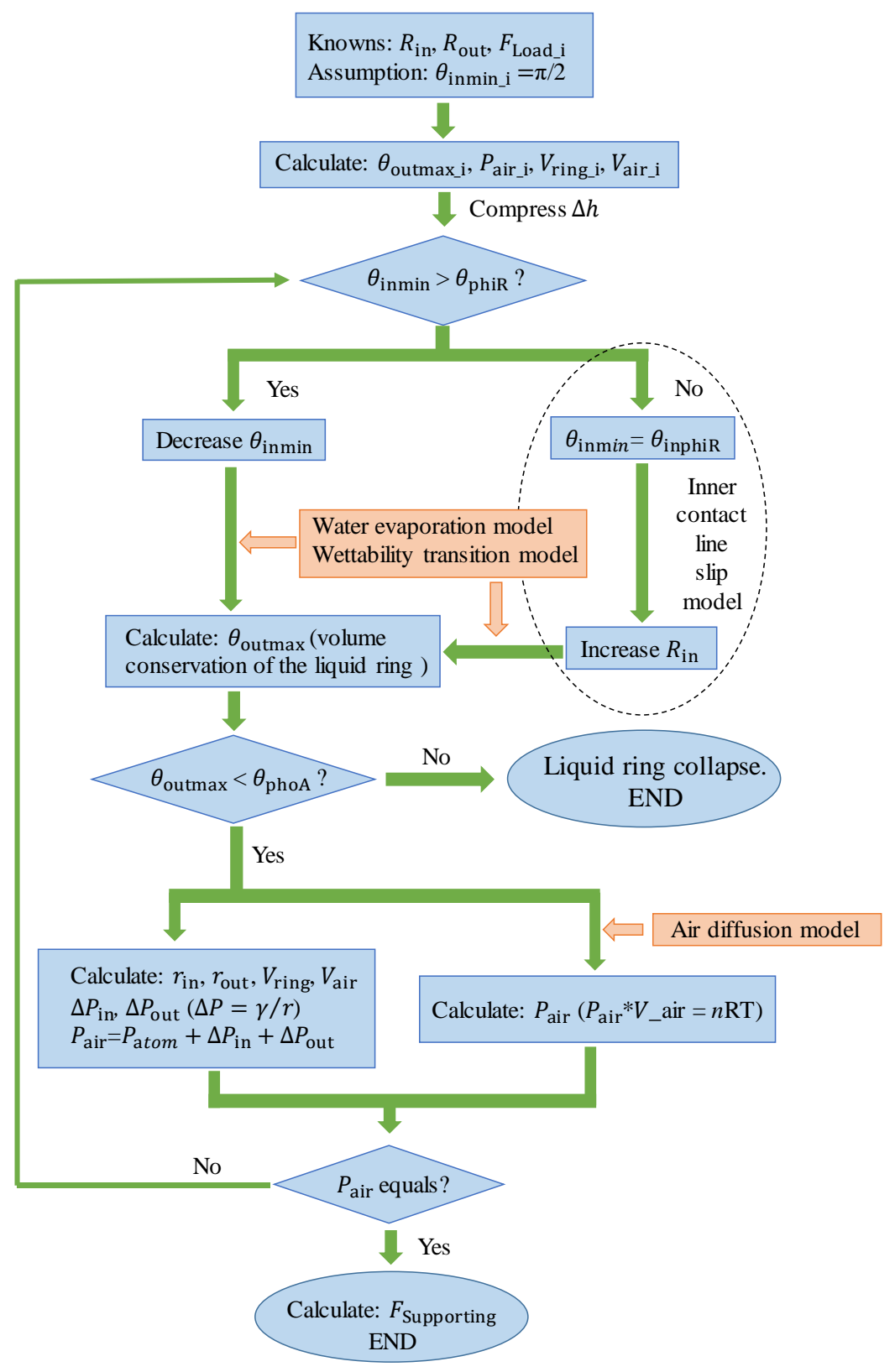

Fig. 3. Flow chart of theoretical model for the stiffness of the bearing. 


\subsection{Liquid evaporation model}

As the bearing tested in this study is open to the environment, the liquid in the liquid ring evaporates during the experiments which reduces the supporting force of the bearing. A liquid ring evaporation model is built to take this influence into account. In this model the liquid/air interface was assumed to be flat and without misalignment. The amount of liquid evaporated per second $\left(L_{e}\right)$ is calculated using the following equation[25]:

$$
L_{e}=\alpha \cdot \mathrm{A} \cdot\left(X_{s}-X\right) / 3600
$$

where $\alpha=(25+19 \cdot \mathrm{v})$ is the liquid evaporation coefficient, $\mathrm{v}$ is the air flow velocity around the bearing, $\mathrm{A}$ is the area of the liquid/air interface from which the liquid evaporates, $X_{S}$ and $X$ are the maximum and the actual humidity ratio (defined as the ratio between the mass of liquid vapor to the mass of the dry air) of the surrounding environment. In the experiment, the humidity measured was relative humidity $(\mathrm{RH})$ and it was transformed to provide actual humidity values to be used to compute the current evaporation rates.

\subsection{Air diffusion model}

When the bearing was compressed, the pressure inside the air cushion was higher than the atmospheric pressure. Thus the air was diffusing through the liquid ring into the atmosphere gradually. This will cause a decrease to the supporting force of the bearing. Here this effect is evaluated using an air diffusion model. In this model the menisci of the liquid ring are also assumed as in the first approximation to be flat and without misalignment. The diffusion of gas $i$ in the liquid ring is governed by Fick's First Law of diffusion:

$$
\frac{\partial C_{j}}{\partial t}=D_{j} \cdot \nabla^{2} C_{j}
$$

where $C_{j}=K_{H j} \cdot P_{j}$ is the concentration of gas $j$ in the liquid ring, $K_{H j}$ and $P_{j}$ are Henry's constant and the partial pressure of gas $j$ respectively, $t$ is time and $D_{j}$ is the diffusion coefficient of gas $j$ in liquid (water).

The molar mass of gas $j$ diffused through the liquid ring $\left(\Delta n_{j}\right)$ at time $t$ is:

$$
\Delta n_{j}=\int_{\varphi=0}^{\varphi=2 \pi} \int_{y=0}^{y=h} \int_{0}^{t} D_{j} \cdot \nabla C_{j} \cdot d \varphi \cdot d y \cdot d t
$$

Using equation (20) the molar mass of $\mathrm{O}_{2}$ and $\mathrm{N}_{2}$, which are the two major components of air, diffused through the liquid ring were calculated. The equations were solved using the CrankNicholson[26] finite difference method, where 100 segments were used in the simulation domain to obtained accurate results.

\subsection{The wettability transition model (slip model)}

Due to the pinning effect of the energy barrier on the contact line, the contact angle at the boundary of the hydrophilic and superhydrophobic surfaces ranges from the contact angle on the hydrophilic surface to that on the superhydrophobic surface. This transition occurs within a band whose width is determined by the coated pattern on the bearing surfaces. Fig. 4(a) shows the variation of the contact angle of a liquid bridge confined by alternating hydrophilic and superhydrophobic patterns as used in this study. Here, the contact line moves slightly as the contact angle changes when the liquid bridge is squeezed. However, due to the limitation of the small gap, it is very difficult to obtain accurate contact angle measurements of the liquid bridge. Thus no quantitative results were obtained from Fig. 4(a). Fig. 4 (b) shows this transition schematically. Through SEM images (see in Fig. 4 (c)), the width of the 
transition band for the patterns used in this study is obtained which is about 200 microns. A linear variation of the relative location of the contact line as a function of the contact angle in the wettability transition region is hypothesised. It is assumed that the contact angle was $90^{\circ}$ at the nominal diameter $\left(R_{\text {in }}=16 \mathrm{~mm}\right.$ and $\left.R_{\text {out }}=18 \mathrm{~mm}\right)$.
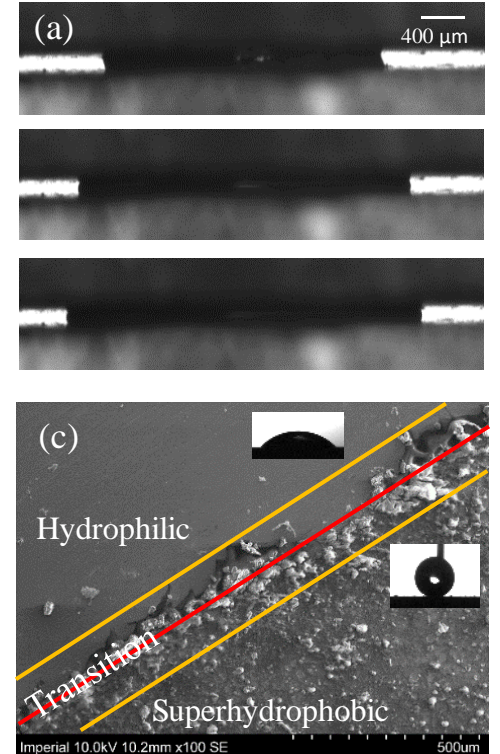

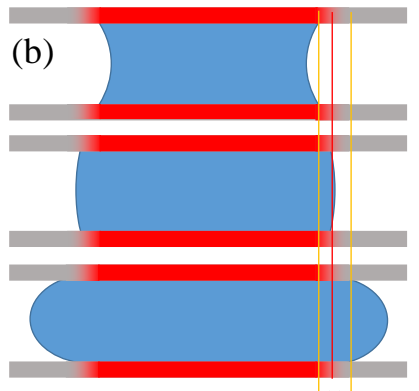

Transition $\overrightarrow{\text { region }}$

Hydrophilic surface

Superhydrophobic surface

Wettability gradient in the transition region

Fig. 4. Transition band between the hydrophilic and superhydrophobic patterns. (a) A liquid bridge between two plates confined by alternating hydrophilic and superhydrophobic patterns. (b) Schematic diagram of the transition band. (c) SEM image of the transition band. 


\section{Results and Discussion}

\subsection{The static supporting force of the bearing}

Fig. 5 (a) shows the numerical results obtained for the maximum $F_{\text {Supporting }}$ of the bearing for different values of misalignment, $\Delta R$. It is shown that as $h$ decreases from 500 to $100 \mu \mathrm{m}$, the maximum $F_{\text {Supporting }}$ of the bearing with $\Delta R$ less than $50 \mu \mathrm{m}$ or no $\Delta R$ increases all the way while those of the bearings with $\Delta R$ larger than $50 \mu \mathrm{m}$ starts to decrease at certain $h$. For a given $h$, the maximum $F_{\text {Supporting }}$ of the bearing decreases with $\Delta R$. In Fig. 5 (b), results containing the whole compressing process for two experiments with different compressing speeds are compared with the numerical results, which only show the maximum $F_{\text {Supporting. }}$

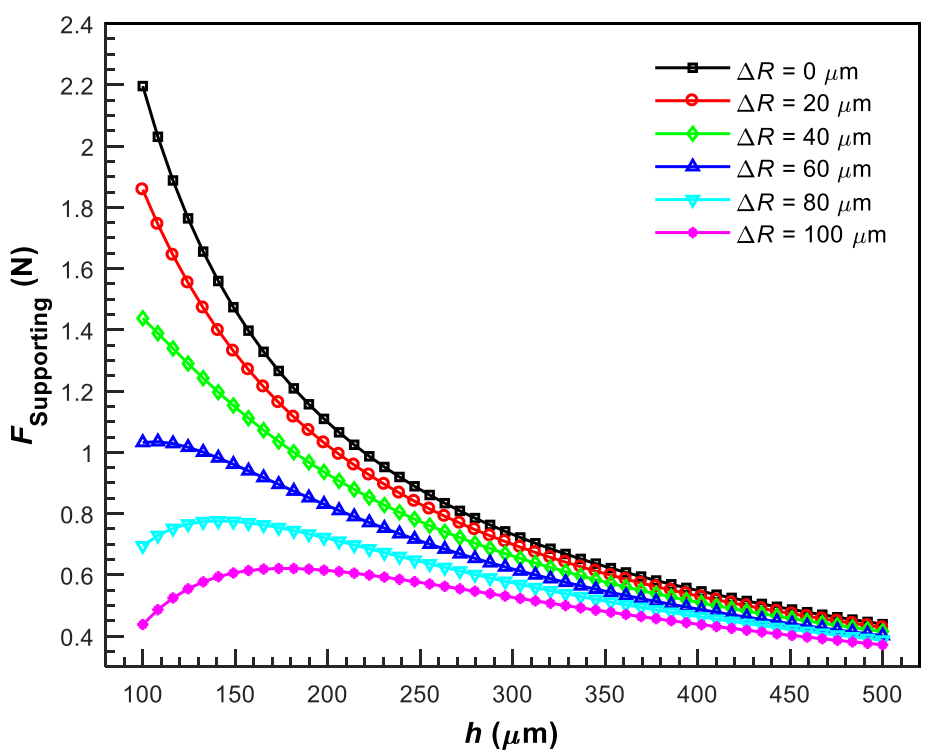

(a)

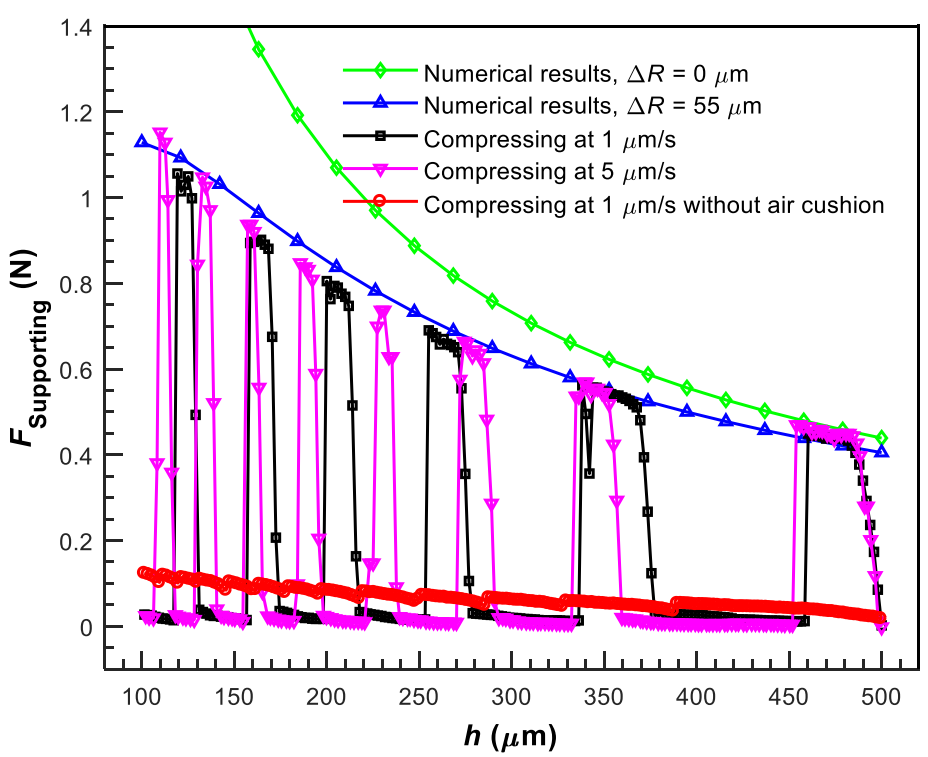

(b)

Fig. 5. The static supporting force of the bearing. (a) Numerical results with different misalignments. (b) Experimental and simulated results.

The experiments started with a liquid ring and an air cushion sealed inside. During compression, the Laplace pressure builds up inside the liquid ring and the air cushion. $F_{\text {Supporting }}$ increases and reaches 
its maximum value when $\theta_{\text {outmax }}$ reached $\theta_{\text {phoA }}$. After that, the liquid ring collapses and a droplet of liquid is expelled from the liquid ring due to the high pressure inside the air cushion. The remaining liquid between the rotor and the stator is not enough to instantaneously form a full liquid ring, but it spreads circumferentially along the hydrophilic strip as the rotor travels downwards to re-establish the full ring support as the system is compressed. During this period, $F_{\text {Supporting }}$ was measured to be around 0 , until the moment the remaining liquid reforms an intact liquid ring and seals an air cushion within it. $F_{\text {Supporting }}$ increases again as the rotor continues downwards.

The results show that the numerical model with a misalignment, $\Delta R$, of $55 \mu \mathrm{m}$ is in reasonable agreement with the experimental measurements. We could also see from the results that the $F_{\text {Supporting }}$ can be improved by reducing $\Delta R$ and this effect is more significant at smaller $h$. It is also evident that the effect of the compressing speed on $F_{\text {Supporting }}$ is very small. As a comparison, the experimental results for the liquid ring bearing without an air cushion (i.e. with an air hole in the stator) is presented in Fig. 5 (b). This shows that the air cushion dramatically increases the supporting force of the bearing.

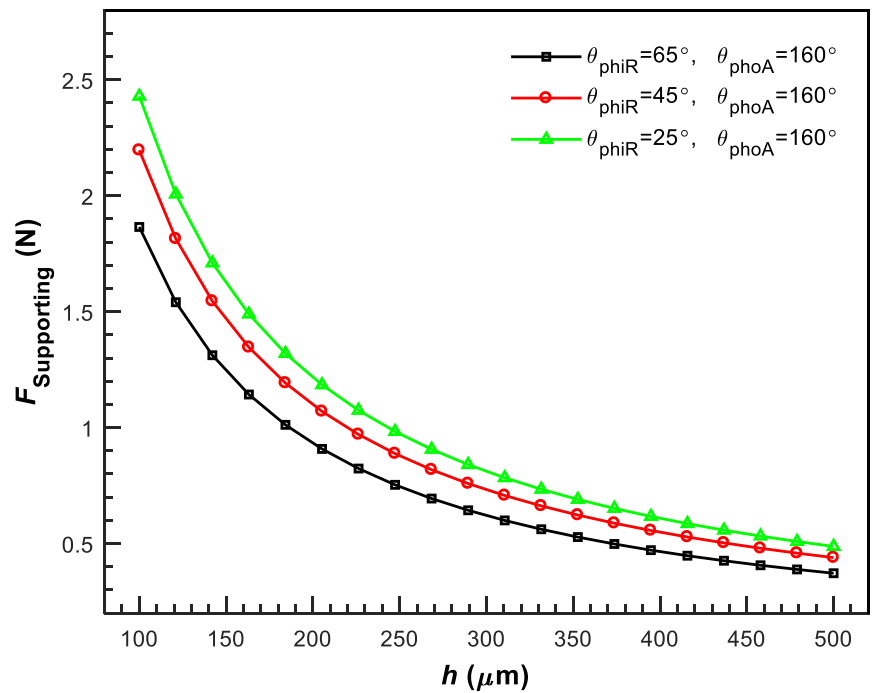

(a)

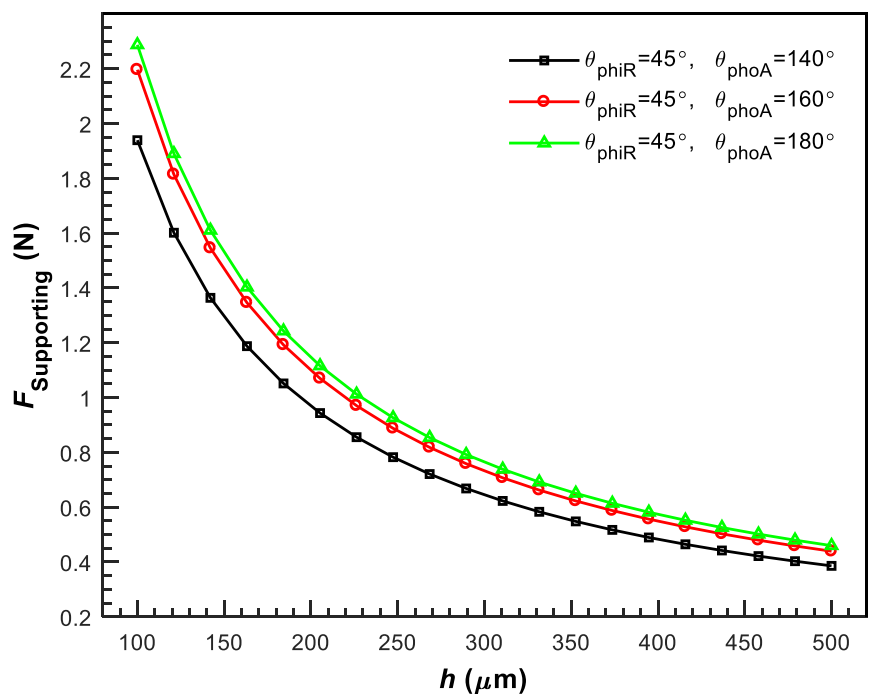

(b)

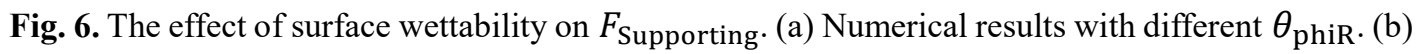
Numerical results with different $\theta_{\text {phoA }}$. 
The effect of wettability, quantified by $\theta_{\text {phiR }}$ and $\theta_{\text {phoA }}$ (i.e. receding contact angle on hydrophilic surface and advancing contact angle on superhydrophobic surface), on $F_{\text {Supporting }}$ of the bearing is studied numerically and the results are shown in Fig. 6. In these simulations, the misalignment $\Delta R$ is set to be 0 . From the results, we can see that $F_{\text {Supporting }}$ of the bearing increases as $\theta_{\text {phiR }}$ decreases and $\theta_{\text {phoA }}$ increases. This means that to increase the supporting force of the bearing, the hydrophilic areas should be as hydrophilic as possible and the superhydrophobic surface should be as hydrophobic as possible. Unlike the effect of misalignment, $\Delta R$, such an effect only shows a slight increase as $h$ decreases.

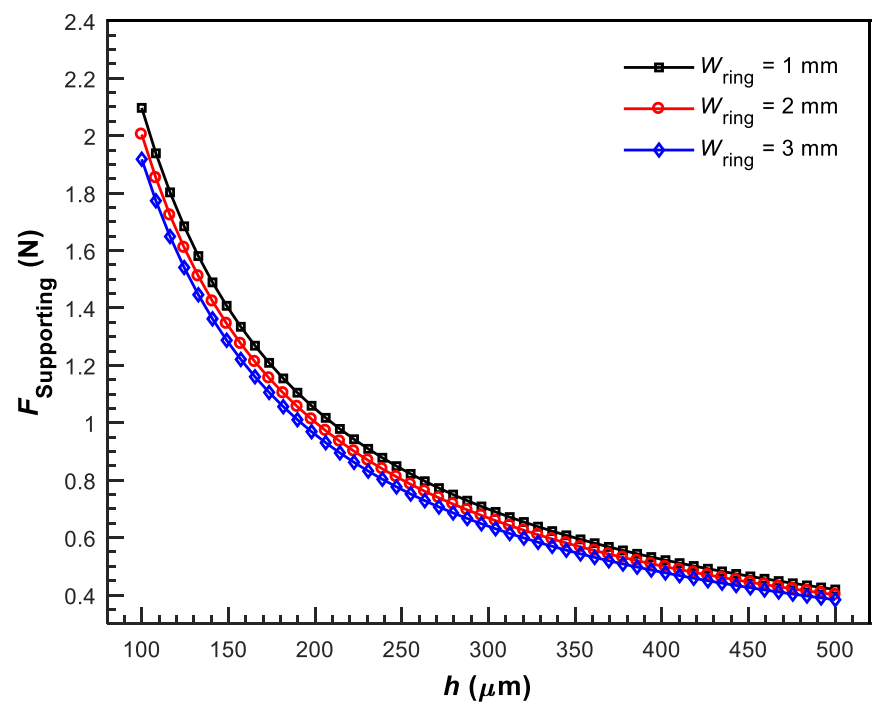

Fig. 7. The effect of $W_{\text {ring }}$ on $F_{\text {Supporting. }}$

The effect of the width of the liquid ring ( $\left.W_{\text {ring }}\right)$ on $F_{\text {Supporting }}$ has also been investigated numerically and the results are shown in Fig. 7. In this numerical model, $R_{\text {out }}$ is the same in all cases and equal to $18 \mathrm{~mm}$. Three different values of $W_{\text {ring }}(1,2$ and $3 \mathrm{~mm})$ were simulated. $\Delta R$ was set to be 0 . It is shown that for the same $h, F_{\text {Supporting }}$ decreases slightly as $W_{\text {ring }}$ increases. This is because, when compressed, the Laplace pressure inside the liquid ring is lower than that in the air cushion (since the former is controlled only by the outer liquid/air interface, while the latter is influenced by both the outer and inner liquid/air interfaces). Therefore, for the same $R_{\text {out }}$, a larger $W_{\text {ring }}$ results in a reduced pressure in the air cushion and thus a smaller $F_{\text {Supporting }}$.

\subsection{The effect of air diffusion}

The diffusion of the two major components of air, nitrogen and oxygen, through the liquid ring was investigated numerically. An example for the diffusion process of nitrogen is shown in Fig. 8. To exaggerate diffusion effects, the initial pressure inside the air cushion was assumed to be $1500 \mathrm{~Pa}$ which is higher than the largest pressure $(1400 \mathrm{~Pa})$ obtained in any of the experiments. The initial concentration of air was assumed to be the saturation concentration at atmosphere pressure. These two assumptions give a higher concentration gradient at the inner liquid/air interface than the experiments, which results in a higher numerical diffusion rate of air through the liquid ring. The diffusion process was simulated for $300 \mathrm{~s}$. Fig. 8 shows how the concentration of nitrogen in the liquid ring $\left(W_{\text {ring }}=\right.$ $2 \mathrm{~mm}$ ) changes with time. Through numerical integration the amount of nitrogen and oxygen that diffused through the liquid rings in $300 \mathrm{~s}$ were calculated. The resulting reduction in air cushion volume was $5.97,3.95$ and $3.64 \times 10^{-8} \%$ for $W_{\text {ring }}=1,2$ and $3 \mathrm{~mm}$ respectively. The effect of such a small loss of air on the supporting force of the bearing can be considered negligible. 


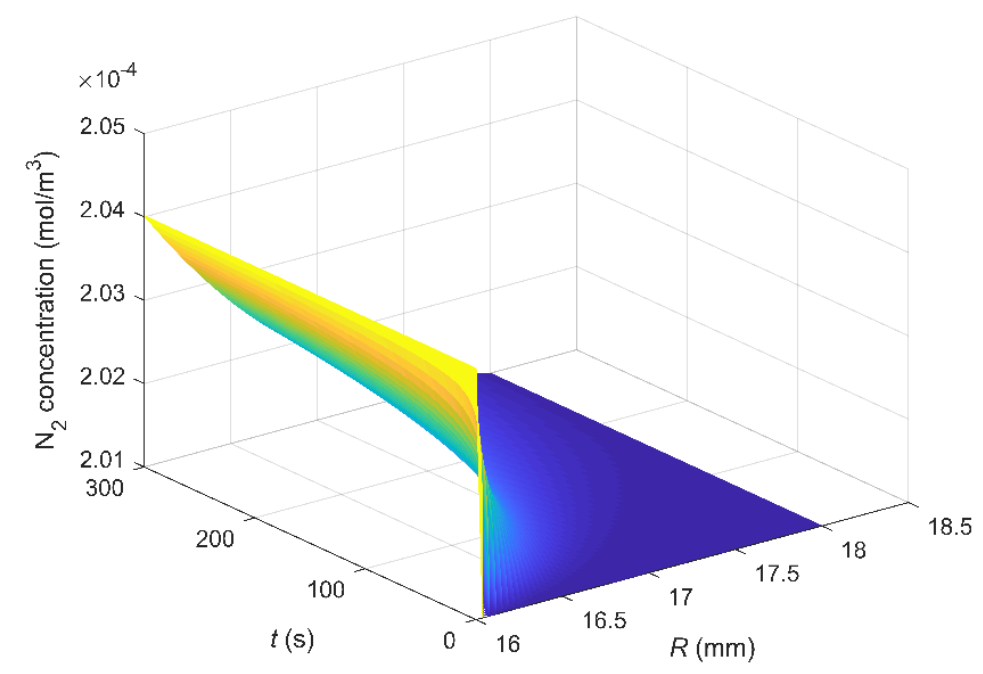

(a)

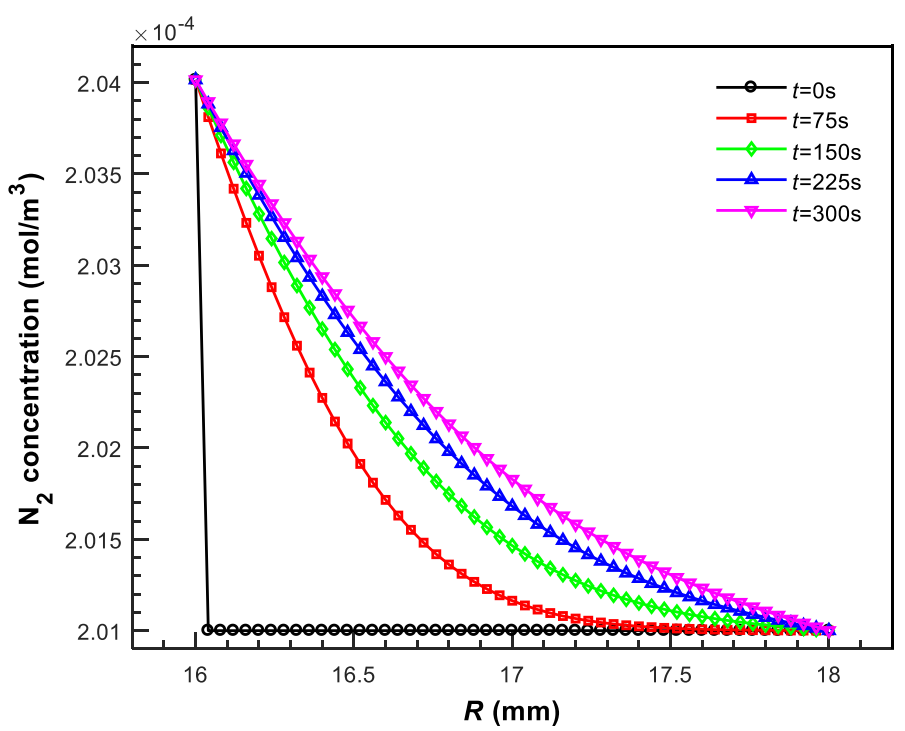

(b)

Fig. 8. Concentration of nitrogen in the liquid ring, showing effect of diffusion. (a) 3D plot showing concentration of $\mathrm{N}_{2}$ as a function of time and position along the liquid ring. (b) $2 \mathrm{D}$ plots showing snapshots in time.

\subsection{The effect of liquid evaporation}

Several tests and simulations were conducted to investigate the effect of liquid evaporation on $F_{\text {Supporting }}$ and the results are shown in Fig. 9 (a). In these tests, $h$ was kept constant and the rotor was rotating slowly at a speed of $0.01 \mathrm{rad} / \mathrm{s}$. The supporting force of the bearing was recorded every $10 \mathrm{~s}$. Six tests were conducted. Half of them were performed with the bearing exposed to air and the relative humidity of the environment was recorded. There was no air flow around the bearing during these experiments except the negligible flow rate induced by the rotation of the rotor. As we can see,

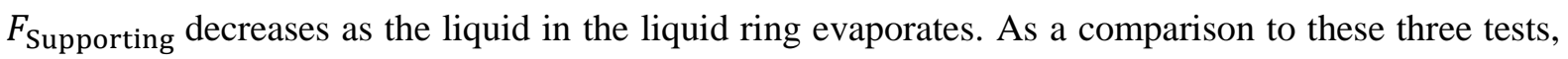
simulations were run under the same conditions but with a zero air flow velocity. As we can see, the numerical and experimental results agree well. The other half of the tests were conducted in a humidified environment. This was achieved by placing a liquid reservoir (i.e. the same liquid as that of the ring) next to the bearing and sealing them both inside a closed chamber. It is shown in Fig. 9(a) that $F_{\text {Supporting }}$ remained approximately constant in these three humidified tests. No corresponding 
simulations to these three tests were conducted since at $100 \%$ relative humidity there would be no evaporation to drive diffusion in the numerical model.

The effect of liquid evaporation on $F_{\text {Supporting }}$ of bearings with different widths $W_{\text {ring }}$ was also investigated numerically and the results shown in Fig. 9(b). In these three simulations, $h$ was $150 \mu \mathrm{m}$, RH was $40 \%$ and outer radius was $18 \mathrm{~mm}$. It is shown that the $F_{\text {Supporting }}$ of the bearing with a smaller $W_{\text {ring }}$ decreases more slowly than that with a larger $W_{\text {ring. }}$. The reason for this is that the liquid in the ring evaporates from the outer liquid/air interface. Under the same environmental conditions, the evaporation speeds remain the same, irrespective of ring width. However, a smaller $W_{\text {ring }}$ leads to a larger air cushion inside the bearing. When the liquid evaporated from the liquid ring, the compressed air cushion expands to make up for the lost volume and the pressure inside the air cushion thus decreases. During this process, due to the compressibility of air, $F_{\text {Supporting }}$ for the bearing with a larger air cushion decreases more slowly.

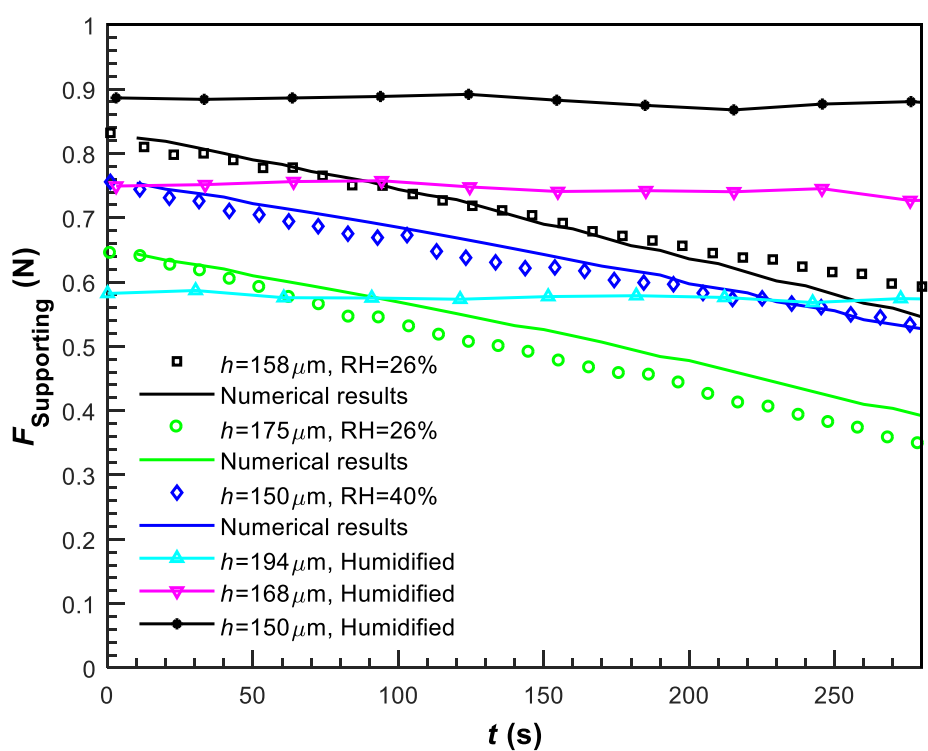

(a)

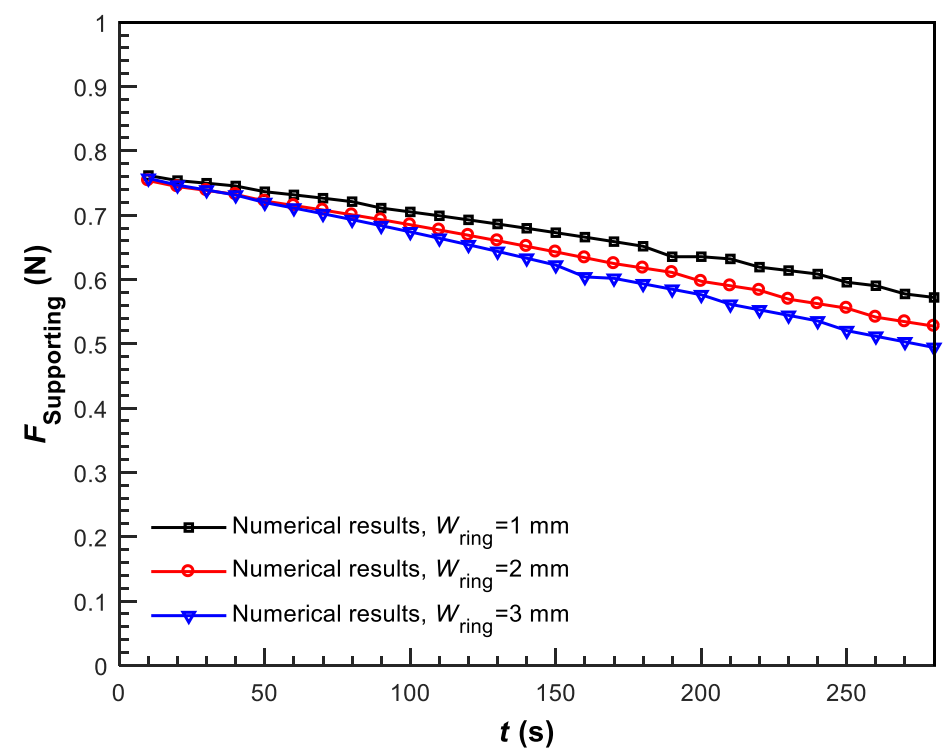

(b)

Fig. 9. Variation in $F_{\text {Supporting }}$ over time ( $h$ constant) showing effect of evaporation. (a) Effect of RH on $F_{\text {Supporting. }}$ (b) Effect of ring width $W_{\text {ring }}$ on $F_{\text {Supporting. }}$. 


\subsection{The stiffness of the bearing}

The stiffness of the bearing was investigated numerically and the results validated against experimental data, as shown in Fig. 10. The numerical model used the first experimental data point after the liquid ring was sealed as the initial condition and modelled the compression process before the liquid ring collapsed (individual events shown in Fig. 5(b)). As we can see when $h$ is larger than 200 $\mu \mathrm{m}$, the numerical results agree well with the experimental results. When $h$ is smaller than $200 \mu \mathrm{m}$, a difference between the numerical and experimental results appears. This is because, in the numerical model, the boundary of the hydrophilic and superhydrophobic rings was assumed to be smooth along the circumferential direction while there is in fact some roughness as can be seen from the SEM image in Fig. 4 (c). This roughness has an amplitude of about $200 \mu \mathrm{m}$. This roughness has an effect on $F_{\text {Supporting }} h$ is reduced. It is also shown that $F_{\text {Supporting }}$ increases almost linearly before it levels out as $h$ decreases.
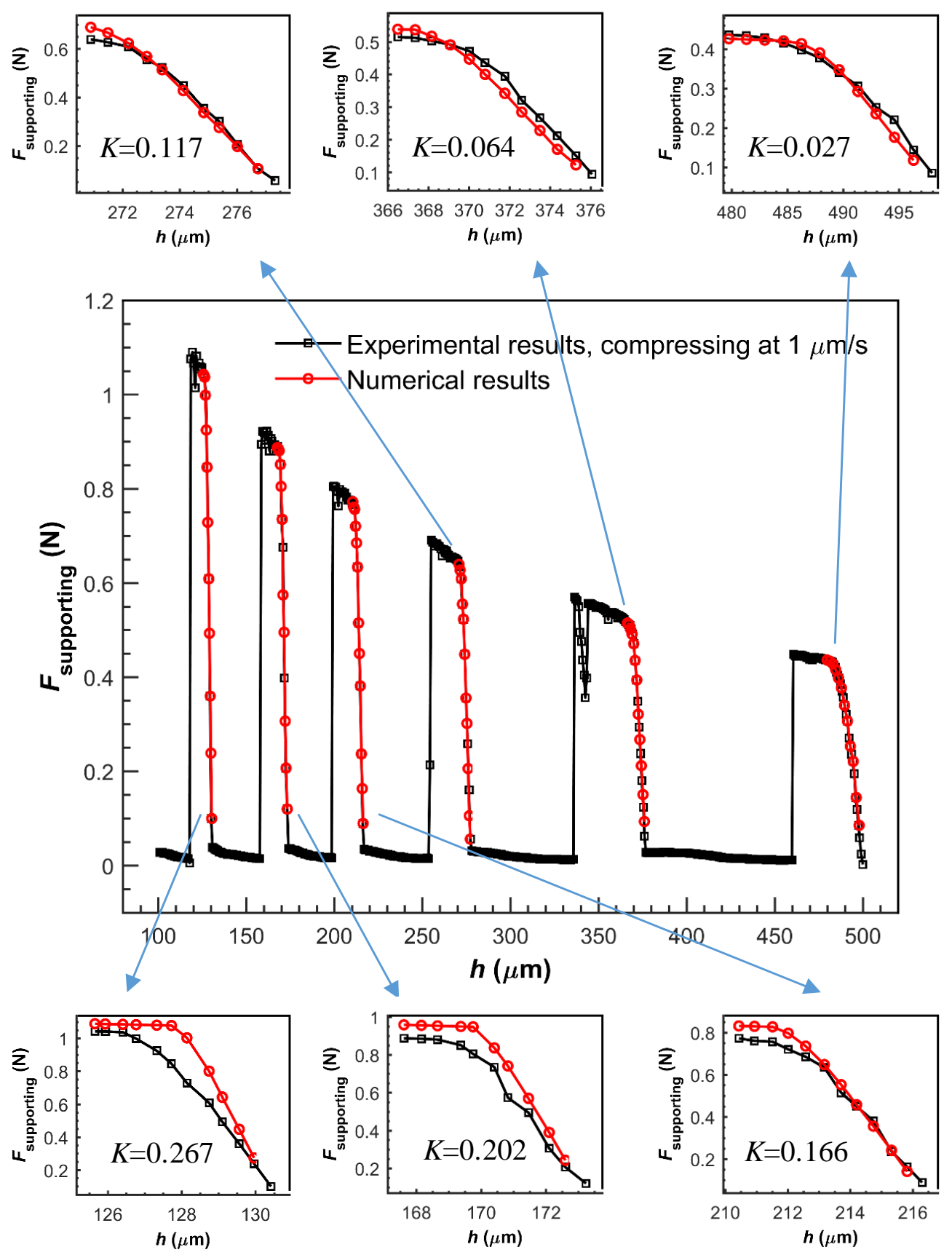

Fig. 10. The stiffness of the bearing: experimental vs. modelling results. 
A linear fitting was used to fit the linear section, $\Delta F_{\text {Supporting }}=-K \cdot \Delta h$, where $K$ was defined as the stiffness coefficient of the bearing, which has a unit of $\mathrm{N} / \mu \mathrm{m}$, while $\Delta F_{\text {Supporting }}$ and $\Delta h$ are the increase of the supporting force and the decrease of the gap height as the bearing is being compressed. We can see that $K$ increases as $h$ decreases, which is a desirable characteristic of a bearing. This is because the air cushion volume decreases as $h$ decreases. Moreover, the percentage reduction in volume increases for the same $\Delta h$ as $h$ decreases and this causes a larger increase in pressure according to the

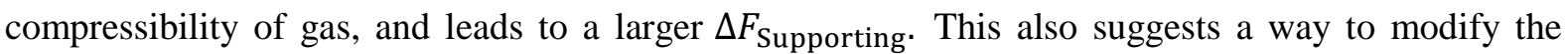
stiffness of the bearing by adding an extra air chamber to the air cushion of the bearing.

The effects of $\Delta R$ and $W_{\text {ring }}$ on the stiffness of the bearing were also investigated numerically and the results shown in Fig. 11. As we can see from Fig.1 (a), the effect of $\Delta R$ on the stiffness is negligible

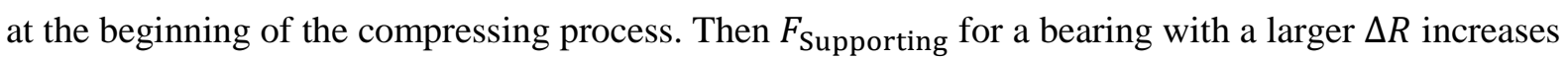
more slowly and reaches its maximum value earlier than that of a bearing with a smaller $\Delta R$. This agrees

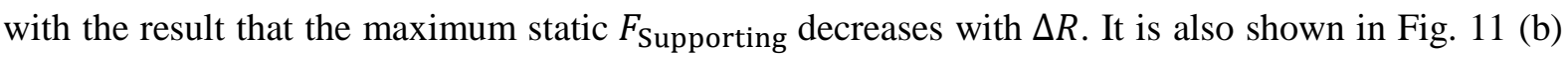
that the effect of $W_{\text {ring }}$ on the stiffness of the bearing is small ( $K$ decreases slightly from 0.123 to 0.114 with $W_{\text {ring }}$ increasing from 1 to $3 \mathrm{~mm}$ ).

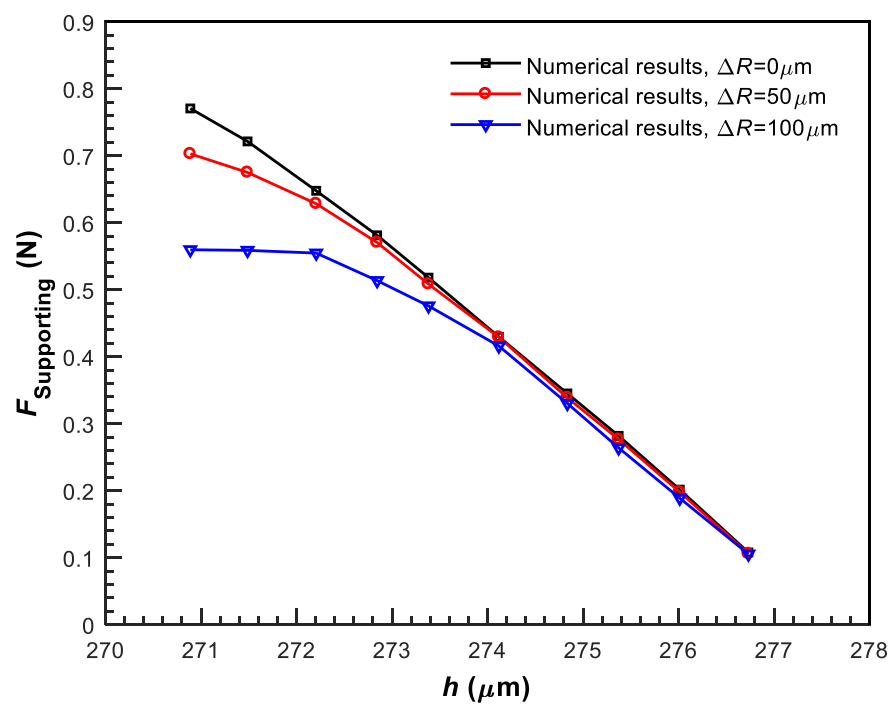

(a)

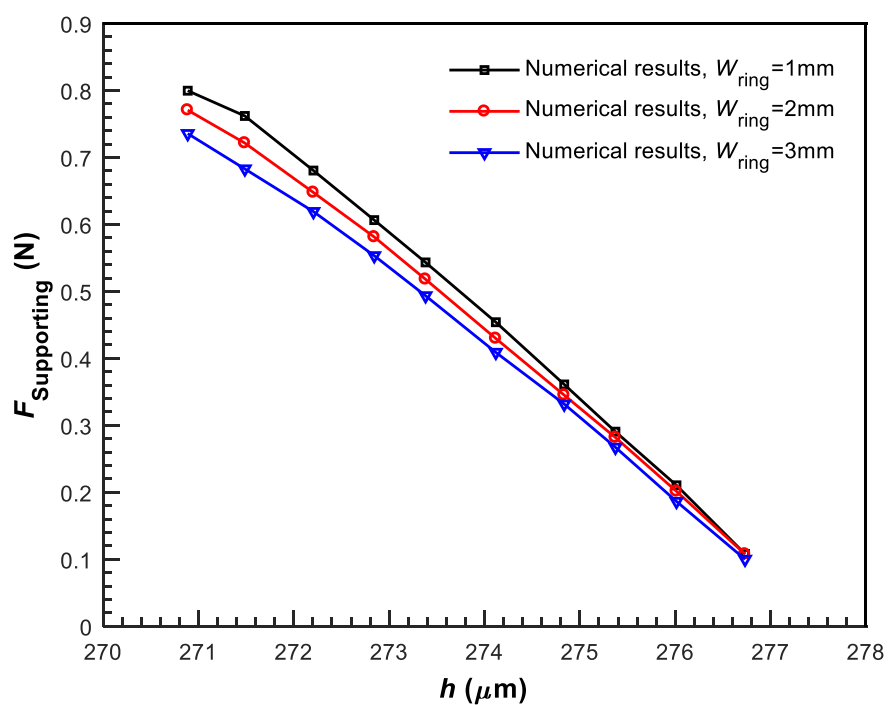

(b)

Fig. 11. The stiffness of the bearing. (a) Effect of $\Delta R$ on stiffness. (b) Effect of $W_{\text {ring }}$ on stiffness. 


\subsection{The dynamic supporting force of the bearing}

Figure 12 shows the dynamic $F_{\text {Supporting }}$ and frictional torque of the bearing measured at different values of $h$. As the rotor rotates, the liquid ring deforms due to centrifugal acceleration. This deformation increases the volume of the air cushion and thus decrease $F_{\text {Supporting. We can see from }}$ Fig. 12 (a) that the dynamic $F_{\text {Supporting }}$ decreases with the rotational speed. It should be noted here that the air diffusion and liquid evaporation also contribute to the decrease of the dynamic $F_{\text {Supporting. The }}$ measured frictional torque $(T)$ of the bearing is plotted against Reynolds number $\left(\operatorname{Re}=\frac{\rho \cdot h \cdot \Omega \cdot R_{\text {out }}}{\eta}\right.$, where $\rho$ is the density of the liquid, $\Omega$ is the rotational speed and $\eta$ is the kinematic viscosity) in Fig. 12 (b) with solid lines. It is shown at the same Re, $T$ increases as $h$ decreases, while for the same $h, T$ increases linearly at small Re. This linear increase agrees well with the theoretical results which assumes a laminar flow in the liquid ring. Based on the laminar assumption, the frictional torque can be calculated with $T=\frac{\pi \cdot \Omega \cdot \eta}{2 h_{r}}\left(r_{o}^{4}-r_{i}^{4}\right)$ and the results are plotted in Fig. 12 (b) using dashed lines. When Re gets larger, $\operatorname{Re}>150$, the system shows a strong nonlinearity. This is due to the energy dispassion caused by the vortex structures formed in the liquid ring flow at relatively large Re as discussed in Ref. [20].

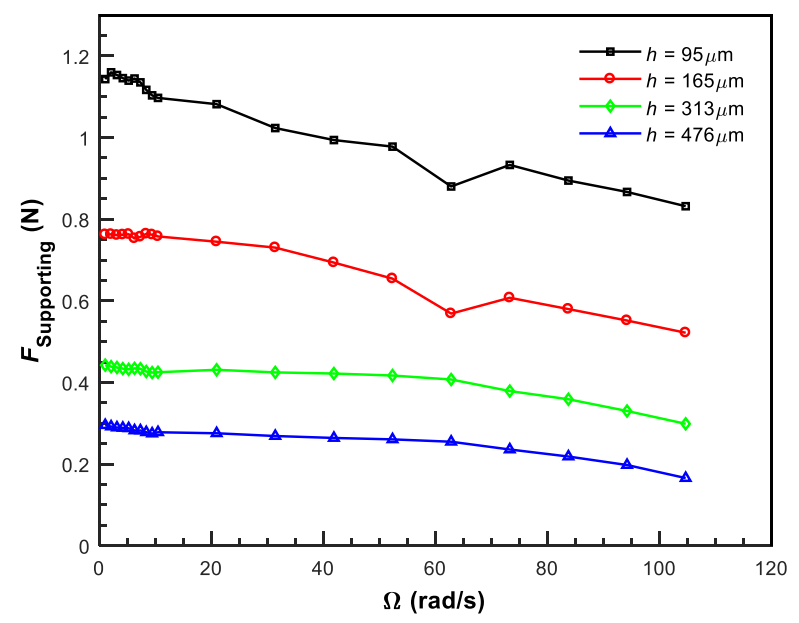

(a)

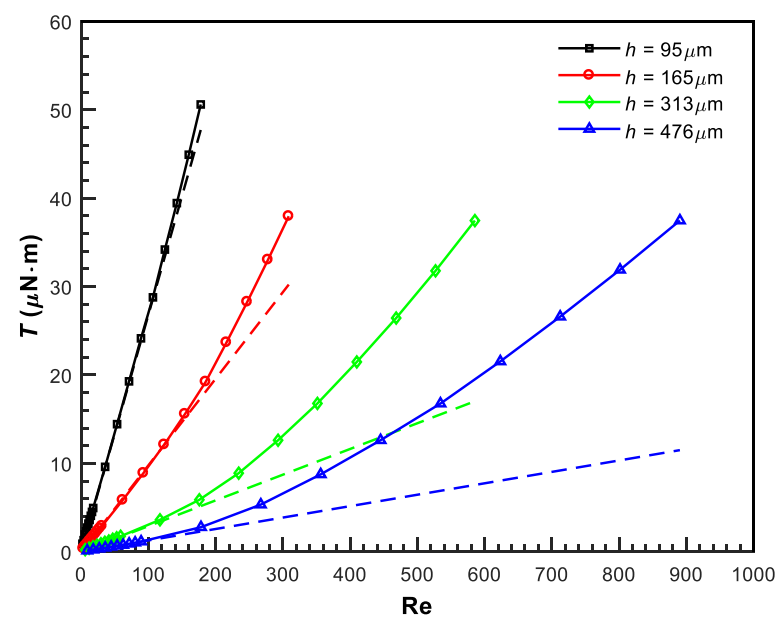

(b)

Fig. 12. Experimental dynamic $F_{\text {Supporting }}$ and frictional torque of the bearing. The solid and dashed lines are the experimental and theoretical results (based on the Laminar assumption),

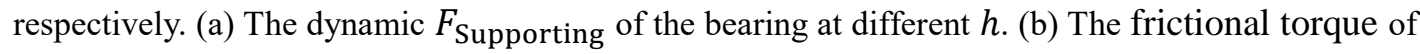
the bearing at different $h$. 


\section{Conclusions}

A liquid ring sealed air bearing has been designed and the effects of different factors on its performance have been investigated both experimentally and numerically. The supporting force of the bearing results from the force induced by the Laplace pressure which dominates at micrometer scale and below. Separated by air and liquid ring, the bearing experiences very small friction and no wear. It was also shown that the air diffusion through the liquid ring is small and could be neglected during the experiments. This gives the bearing an advantage over the conventional air levitated bearings where continuous air supply is needed and an advantage over the liquid ring bearings which has much smaller supporting force and similar frictional torque for the same size and rotational speed.

It has been shown, through a systematic parametric study that the liquid evaporation causes a decrease to the supporting force of the bearing but this decreases at a slower rate when the environmental humidity is increased, which suggests that this problem could be handled by increasing the environmental humidity. Alternatively, ionic liquids with low vapour pressure could be used. The misalignment between the alternating hydrophilic and superhydrophobic rings on the rotor and the stator is an important factor which reduces the supporting force of the bearing, and this effect becomes significant when the misalignment is comparable to or smaller than the gap height. Thus the misalignment should be avoided when constructing such a bearing. With the same outer diameter, the supporting force of the bearing decreases slightly as the width of the liquid ring increases while the frictional torque increases. Thus, the width of the liquid ring should be as small as possible. However, it should be noted that reducing the width of the liquid ring may increase the vulnerability of the bearing to evaporation. The proposed model and the experimental results obtained in this study can be used to design new low cost and passive solutions using liquid ring sealed bearings for small system and devices (such as MEMS), for which the performance of the bearing is maximised.

\section{Acknowledgments}

The project was funded by the CSC Imperial Scholarship (Grant no. 201700260048). The authors also acknowledge the support received by the Engineering and Physical Sciences Research Council (EPSRC) via Professor Dini's Established Career Fellowship, EP/N025954/1. All data are available on request by emailing the corresponding author or tribology@imperial.ac.uk. 


\section{References}

[1] Kralchevsky PA, Nagayama K. Capillary interactions between particles bound to interfaces, liquid films and biomembranes. Advances in colloid and interface science. 2000;85:145-92.

[2] Oettel M, Dietrich S. Colloidal interactions at fluid interfaces. Langmuir. 2008;24:1425-41.

[3] Maboudian R, Carraro C. Surface chemistry and tribology of MEMS. Annu Rev Phys Chem. 2004;55:35-54.

[4] Schiffer P. Granular physics: A bridge to sandpile stability. Nature Physics. 2005;1:21.

[5] Mastrangeli M. The Fluid Joint: The Soft Spot of Micro- and Nanosystems. Adv Mater. 2015;27:4254-72.

[6] Malaquin L, Kraus T, Schmid H, Delamarche E, Wolf $\mathrm{H}$. Controlled particle placement through convective and capillary assembly. Langmuir. 2007;23:11513-21.

[7] Flauraud V, Mastrangeli M, Bernasconi GD, Butet J, Alexander DT, Shahrabi E, et al. Nanoscale topographical control of capillary assembly of nanoparticles. Nature nanotechnology. 2017;12:73.

[8] Gat A, Navaz H, Gharib M. Dynamics of freely moving plates connected by a shallow liquid bridge. Phys Fluids. 2011;23:097101.

[9] Dhull RK, Fuller L, Kao P-C, Liao Y-C, Lu Y-W. Two degree-of-freedom micromirror actuation using thermocapillary effect in liquid droplets. Sensors and Actuators A: Physical. 2011;168:162-7.

[10] Chan ML, Yoxall B, Park H, Kang Z, Izyumin I, Chou J, et al. Low Friction Liquid Bearing MEMS Micromotor. 2011 leee 24th International Conference on Micro Electro Mechanical Systems2011. p. 1237-40.

[11] Sun G, Liu TL, Sen P, Shen W, Gudeman C, Kim C-JCJ. Electrostatic Side-Drive Rotary Stage on Liquid-Ring Bearing. Journal of Microelectromechanical Systems. 2014;23:147-56.

[12] Yoxall BE, Chan ML, Harake RS, Pan TR, Horsley DA. Rotary Liquid Droplet Microbearing. Journal of Microelectromechanical Systems. 2012;21:721-9.

[13] Chan ML, Yoxall B, Park H, Kang Z, Izyumin I, Chou J, et al. Design and characterization of MEMS micromotor supported on low friction liquid bearing. Sensors and Actuators a-Physical. 2012;177:1-9. [14] Fuchiwaki O, Kumagai K. Development of wet tweezers based on capillary force for complexshaped and heterogeneous micro-assembly. 2013 IEEE/RSJ International Conference on Intelligent Robots and Systems: IEEE; 2013. p. 1003-9.

[15] Fantoni G, Hansen HN, Santochi M. A new capillary gripper for mini and micro parts. CIRP Annals. 2013;62:17-20.

[16] Lian G, Seville J. The capillary bridge between two spheres: New closed-form equations in a two century old problem. Advances in colloid and interface science. 2016;227:53-62.

[17] Willett CD, Adams MJ, Johnson SA, Seville JP. Capillary bridges between two spherical bodies. Langmuir. 2000;16:9396-405.

[18] Wang LF, Huang BS, He YZ, Rong WB, Sun LN. Simulation and Experiments on the Capillary Force between a Circular Disk and a Parallel Substrate. Chinese Physics Letters. 2017;34.

[19] De Souza EJ, Gao L, McCarthy TJ, Arzt E, Crosby AJ. Effect of Contact Angle Hysteresis on the Measurement of Capillary Forces. Langmuir. 2008;24:1391-6.

[20] Wen J, Dini D, Reddyhoff T. Design and optimization of a liquid ring thrust bearing. Tribology International. 2019.

[21] Shan XC, Zhang QD, Sun YF, Maeda R. Studies on a micro turbine device with both journal- and thrust-air bearings. Microsystem Technologies-Micro-and Nanosystems-Information Storage and Processing Systems. 2007;13:1501-8.

[22] Fu L, Feng Z, Li G. Experimental investigation on overall performance of a millimeter-scale radial turbine for micro gas turbine. Energy. 2017;134:1-9.

[23] Yu M, Lv P, Xu T, Tan X, Li H. Manufacturing of a Compact Micro Air Bearing Device for Power Micro Electro Mechanical System (MEMS) Applications Using Silica Film Assisted Processing. Micromachines. 2018;9:166.

[24] Butt H-J, Kappl M. Normal capillary forces. Advances in colloid and interface science. 2009;146:4860.

[25] The Engineering ToolBox. Evaporation from Water Surface, https://www.engineeringtoolbox.com/evaporation-water-surface-d 690.html; 2004 [Accessed 22 August 2019]. 
[26] Crank J, Nicolson P. A practical method for numerical evaluation of solutions of partial differential equations of the heat-conduction type. Mathematical Proceedings of the Cambridge Philosophical Society: Cambridge University Press; 1947. p. 50-67. 


\section{Appendix}

\section{A. Volume of the liquid ring}

The liquid ring is divided into 4 sections having the same volume $\left(V_{\text {ring/4 }}\right)$. Here $V_{\text {ring/4 }}$ of the section between $\varphi=0$ and $\varphi=\pi / 2$ (see in Fig. 2 (a)) is calculated and the total volume of the liquid ring is $V_{\text {ring }}=4 \cdot V_{\text {ring } / 4}$. The section of the liquid ring again is divided into 2 sections: the outer meniscus (depicted as (1) in Fig. 2 (a) and (b)), the rest body of the liquid ring (depicted as (2) in Fig. 2 (b)). The volume of section (2) $\left(V_{2}\right)$ is calculated using the vertical column defined by the lower pattern $\left(V_{\text {column }}\right)$ minus the volume $\left(V_{3}\right)$ of the inner meniscus (depicted as (3) in Fig. 2(a) and (b)). Thus the volume of the liquid ring is:

$$
V_{\text {ring }}=4 \cdot V_{\text {ring } / 4}=4 \cdot\left(V_{1}+V_{\text {column }}-V_{3}\right)
$$

Here the calculation of the volume of section (1) $\left(V_{1}\right)$ was shown:

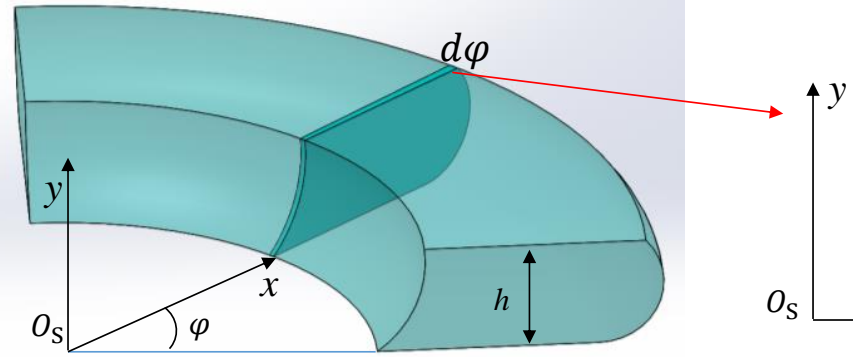

(a)

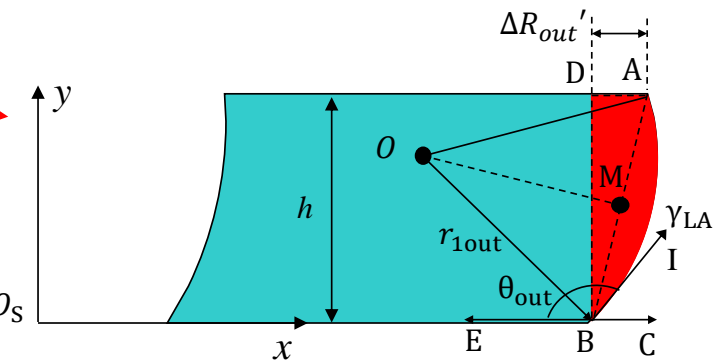

(b)

Fig. A.1. The volume of section (1). (a) Coordinate system used for calculation. (b) Infinitesimal element of the liquid ring.

The $O_{\mathrm{S}}$ coordinate system is shown in Fig. A.1 (a). As discussed in the main text, the curvature radius of the outer meniscus on the cross sectional plane ( $\left.r_{1 \text { out }}\right)$ at different $\varphi$ is constant and is calculated using Eq. (7). The local misalignment of the outer contact line $\left(\Delta R_{\text {out }}{ }^{\prime}\right)$ is calculated using Eq. (10). The gap height $(h)$ is known. Then the local outer contact angle $\theta_{\text {out }}$ is calculated:

$$
\theta_{\text {out }}=270^{\circ}-\arctan \left(\frac{h}{\Delta R_{\text {out }}{ }^{\prime}}\right)-\arccos \left(\frac{\sqrt{\Delta R_{\text {out }}{ }^{2}+h^{2}}}{2 \cdot r_{1 \text { out }}}\right)
$$

Then the coordinates of $O$ were calculate:

$$
\begin{gathered}
x_{O}=R_{\text {out }}-\frac{\Delta R_{\text {out }}{ }^{\prime}}{2}-r_{1 \text { out }} \cdot \cos \left(\theta_{\text {out }}-\frac{\pi}{2}\right) \\
y_{O}=r_{1 \text { out }} \cdot \sin \left(\theta_{\text {out }}-\frac{\pi}{2}\right)
\end{gathered}
$$

In the $O_{\mathrm{S}}$ coordinate system, the profile of the outer liquid/air interface was depicted:

$$
\left(x-x_{O}\right)^{2}+\left(y-y_{O}\right)^{2}=r_{1 \text { out }}^{2}
$$

Then volume of the annulus defined by the red area in Fig. S1 (b) and the $y$ axis as the axle of revolution can be calculated:

$$
V=\int_{0}^{h}\left(\pi \cdot x^{2}-\pi \cdot\left(R_{\text {out }}-\frac{\Delta R_{\text {out }}{ }^{\prime}}{2}\right)^{2}\right) d y
$$

where $x$ was calculated using the transformation of Eq. (A.5): 


$$
x=x_{O}+\sqrt{r_{1 \mathrm{out}}^{2}-\left(y-y_{O}\right)^{2}}
$$

Then the volume of section (1) is:

$$
V_{1}=\int_{0}^{\frac{\pi}{2}} \frac{\int_{0}^{h}\left(\pi \cdot\left(x_{O}+{\sqrt{r_{1 \text { out }}{ }^{2}-\left(y-y_{O}\right)^{2}}}^{2}-\pi \cdot\left(R_{\text {out }}-\frac{\Delta R_{\text {out }}{ }^{\prime}}{2}\right)^{2}\right) d y\right.}{2 \cdot \pi} d \varphi
$$

To calculate the volume of section (2) $\left(V_{2}\right)$, first the volume of the vertical column defined by the lower pattern $\left(V_{\text {column }}\right)$ is calculated:

$$
V_{\text {column }}=\int_{0}^{2 \cdot \pi} \frac{\pi \cdot\left(\mathrm{HO}_{S}{ }^{2}-\mathrm{KO}_{S}{ }^{2}\right)}{2 \cdot \pi} d \varphi
$$

where $\mathrm{HO}_{S}$ and $\mathrm{KO}_{S}$ are calculated:

$$
\begin{aligned}
& \mathrm{H} O_{\mathrm{S}}=\cos (\pi-\varphi) \cdot \Delta R / 2+\sqrt{[\cos (\pi-\varphi)]^{2} \cdot \frac{\Delta R^{2}}{4}+R_{\text {out }}^{2}-\frac{\Delta R^{2}}{4}} \\
& \mathrm{KO}_{\mathrm{S}}=\cos (\pi-\varphi) \cdot \Delta R / 2+\sqrt{[\cos (\pi-\varphi)]^{2} \cdot \frac{\Delta R^{2}}{4}+R_{\mathrm{in}}{ }^{2}-\frac{\Delta R^{2}}{4}}
\end{aligned}
$$

The calculation of the volume of the inner meniscus $V_{3}$ is similar to $V_{1}$ and is not presented here.

\section{B. Volume of the air cushion}

As with the liquid ring, the air cushion is also divided into 4 sections each having the same volume $\left(V_{\text {air } / 4}\right)$. Here $V_{\text {air } / 4}$ of the section between $\varphi=0$ and $\varphi=\pi / 2$ (shown in Fig. 2 (a))_is calculated and the total volume of the air cushion was $V_{\mathrm{air}}=4 \cdot V_{\mathrm{air} / 4}$. The section of the air cushion is calculated using the vertical column defined by the lower inner contact line $\left(V_{\text {column_air }}\right)$ plus the volume $\left(V_{3}\right)$ of the inner meniscus (depicted as (3) in Fig. 2 (a) and (b)). Thus the volume of the air cushion is:

$$
V_{\text {air }}=4 \cdot V_{\text {air } / 4}=4 \cdot\left(V_{\text {column_air }}+V_{3}\right)
$$

The volume of the vertical column defined by the lower inner contact line $\left(V_{\text {column_air }}\right)$ is calculated:

$$
V_{\text {column_air }}=\int_{0}^{2 \cdot \pi} \frac{\pi \cdot \mathrm{KO}_{S}^{2}}{2 \cdot \pi} d \varphi
$$

where $\mathrm{KO}_{S}$ is calculated using Eq. (A.11). The calculation of the volume of the inner meniscus $V_{3}$ is similar to $V_{1}$ which is presented in appendix A. 